\title{
Front Matter: Volume 10717
}

, "Front Matter: Volume 10717," Proc. SPIE 10717, Saratov Fall Meeting 2017: Laser Physics and Photonics XVIII; and Computational Biophysics and Analysis of Biomedical Data IV, 1071701 (1 May 2018); doi:

10.1117/12.2325795

SPIE. Event: Saratov Fall Meeting 2017, 2017, Saratov, Russian Federation 


\title{
Saratov Fall Meeting 2017
}

\section{Laser Physics and Photonics XVIII; and Computational Biophysics and Analysis of Biomedical Data IV}

\author{
Vladimir L. Derbov \\ Dmitry E. Postnov \\ Editors
}

\section{6-30 September 2017 \\ Saratov, Russian Federation}

Sponsored by

Russian Foundation for Basic Research (Russian Federation) • Russian Academy of Sciences (Russian Federation) • SPIE • OSA-The Optical Society • IEEE • Russian Technology Platform "The Medicine of the Future" (Russian Federation) • Russian Technology Platform "Photonics" (Russian Federation) • European Technology Platform "Photonics21"

Published by

SPIE 
The papers in this volume were part of the technical conference cited on the cover and title page. Papers were selected and subject to review by the editors and conference program committee. Some conference presentations may not be available for publication. Additional papers and presentation recordings may be available online in the SPIE Digital Library at SPIEDigitallibrary.org.

The papers reflect the work and thoughts of the authors and are published herein as submitted. The publisher is not responsible for the validity of the information or for any outcomes resulting from reliance thereon.

Please use the following format to cite material from these proceedings:

Author(s), "Title of Paper," in Saratov Fall Meeting 2017: Laser Physics and Photonics XVIII; and Computational Biophysics and Analysis of Biomedical Data IV, edited by Vladimir L. Derbov, Dmitry E. Postnov, Proceedings of SPIE Vol. 10717 (SPIE, Bellingham, WA, 2018) Seven-digit Article CID Number.

ISSN: 1605-7422

ISSN: $2410-9045$ (electronic)

ISBN: 9781510620032

ISBN: 9781510620049 (electronic)

Published by

SPIE

P.O. Box 10, Bellingham, Washington 98227-0010 USA

Telephone +1 3606763290 (Pacific Time) · Fax +1 3606471445

SPIE.org

Copyright @ 2018 , Society of Photo-Optical Instrumentation Engineers.

Copying of material in this book for internal or personal use, or for the internal or personal use of specific clients, beyond the fair use provisions granted by the U.S. Copyright Law is authorized by SPIE subject to payment of copying fees. The Transactional Reporting Service base fee for this volume is $\$ 18.00$ per article (or portion thereof), which should be paid directly to the Copyright Clearance Center (CCC), 222 Rosewood Drive, Danvers, MA 01923. Payment may also be made electronically through CCC Online at copyright.com. Other copying for republication, resale, advertising or promotion, or any form of systematic or multiple reproduction of any material in this book is prohibited except with permission in writing from the publisher. The CCC fee code is 1605$7422 / 18 / \$ 18.00$.

Printed in the United States of America.

Publication of record for individual papers is online in the SPIE Digital Library.

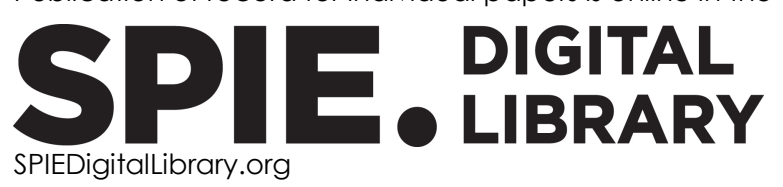

Paper Numbering: Proceedings of SPIE follow an e-First publication model. A unique citation identifier (CID) number is assigned to each article at the time of publication. Utilization of CIDs allows articles to be fully citable as soon as they are published online, and connects the same identifier to all online and print versions of the publication. SPIE uses a seven-digit CID article numbering system structured as follows:

- The first five digits correspond to the SPIE volume number.

- The last two digits indicate publication order within the volume using a Base 36 numbering system employing both numerals and letters. These two-number sets start with $00,01,02,03,04$, 05, 06, 07, 08, 09, 0A, OB ... 0Z, followed by 10-1Z, 20-2Z, etc. The CID Number appears on each page of the manuscript. 


\title{
Contents
}

\author{
ix Authors \\ xiii Conference Committee \\ $\mathrm{xV} \quad$ Introduction \\ xix Organizers
}

\section{LASER SYSTEMS AND NOVEL APPLICATIONS}

1071702 The choice of the optimal approximation in the kinetic description of the vacuum creation of electron-positron plasma in strong laser fields [10717-13]

1071703 Modification of the laser triangulation method for measuring the thickness of optical layers [10717-87]

1071704 Optimization of silicon waveguides for gas detection application at mid-IR wavelengths [10717-44]

$1071705 \quad \mathbf{O}^{2}(\mathbf{a} 1 \Delta)$ vibrational kinetics in oxygen-iodine laser [10717-201]

$1071706 \quad \mathbf{O}^{2}\left(\mathbf{b}^{1} \Sigma^{+} \mathrm{g}\right)$ relaxation in active medium of oxygen-iodine laser [10717-182]

1071707 Broadband tunable mid-IR $\mathrm{Cr}^{2+}:$ CdSe lasers for medical applications [10717-99]

1071708 Self-mixing laser diode included in scanning microwave microscope to the control of probe nanodisplacement [10717-163]

1071709 Influence of temperature on the spectral characteristics of semiconductor lasers in the visible range [10717-92]

10717 OA Using phase locking for improving frequency stability and tunability of THz-band gyrotrons [10717-135]

10717 OB Synchronization and control of external-cavity laser diodes [10717-162]

\section{LASER-ACTIVE AND NONLINEAR OPTICAL MEDIA AND INTERACTIONS}

10717 OC Ramsey scheme for coherent population resonance detection in the optically dense medium [10717-3]

10717 OD Comparison of light harmonic generation in Al and Ge consisted silicate materials [10717-89] 
10717 OE Multi-peaks scattering of light in glasses [10717-91]

10717 OF Model of quantum kinetics of spin-orbit coupled two-dimensional electron gas in the presence of strong electromagnetic field [10717-175]

$107170 \mathrm{O}$ The improved z-scan technique: potentialities of the additional right-angle scattering channel and the input polarization control [10717-118]

$10717 \mathrm{OH} \quad$ Amplitude and phase measurements based on low-coherence interferometry with acousto-optic spectral image filtration [10717-172]

10717 Ol The measurement of argon metastable atoms in the barrier discharge plasma [10717-164]

\section{BEAM AND PULSE PROPAGATION, IMAGE FORMATION}

$107170 \mathrm{~J}$ Electromagnetically induced transparency in the case of elliptic polarization of interacting fields [10717-27]

10717 OK Modelling of the nonlinear soliton dynamics in the ring fibre cavity [10717-165]

$10717 \mathrm{OL}$ Investigation of focusing features of a spiral binary axicon [10717-155]

10717 OM Sharp focusing of laser light by multilayer cylinders with circular cross-section [10717-181]

10717 ON Tight focusing of a nonhomogeneously polarized optical vortex [10717-174]

1071700 Stimulated fission of high-order optical breather via pairwise interaction of solitons in model of nonlinear Schrödinger equation with variable coefficients [10717-142]

10717 OP Transformation of an optical pulse shape in a phototropic medium [10717-139]

$107170 Q$ Experimental investigation of complex circular Airy beam characteristics [10717-154]

\section{QUANTUM OPTICS, CAVITY QED, AND NON-CLASSICAL LIGHT}

10717 OR Generalized Tavis-Cummings models and quantum networks [10717-186]

10717 OS The description of two-photon Rabi oscillations in the path integral approach [10717-173]

10717 OT Dynamics of atom-field entanglement for Tavis-Cummings models [10717-170]

10717 OU Atom-atom entanglement in the double Jaynes-Cummings model [10717-171]

10717 OV Light with orbital angular momentum and encryption algorithms [10717-166]

10717 OW Near-field excitation exchange between motionless point atoms located near the conductive surface [10717-22] 
$107170 \mathrm{X}$ Influence of dipole-dipole interaction and detuning on entanglement dynamics in twoatom Jaynes-Cummings model [10717-180]

\section{COMPUTATIONAL APPROACHES AND NUMERICAL SIMULATIONS IN PHOTONICS}

10717 OY Algorithm for lens calculations in the geometrized Maxwell theory [10717-100]

$10717 \mathrm{OZ}$ Calculation of normal modes of the closed waveguides in general vector case [10717-136]

1071710 One-dimensional "atom" with zero-range potential perturbed by finite sequence of zeroduration laser pulses [10717-183]

1071711 Simulation of light propagation in the thin-film waveguide lens [10717-184]

1071712 Finite element method for calculating spectral and optical characteristics of axially symmetric quantum dots [10717-177]

1071713 The Riemannian geometry is not sufficient for the geometrization of the Maxwell's equations [10717-156]

\section{ELECTRODYNAMICS OF PHOTONIC STRUCTURES AND METAMATERIALS}

1071714 Backward and forward plasmons in symmetric structures [10717-11]

1071715 Diffraction of a plane wave on two-dimensional conductive structures and a surface wave [10717-28]

1071716 WKB solution $\mathbf{4 \times 4}$ for electromagnetic waves in a planar magnetically anisotropic inhomogeneous layer [10717-49]

1071717 Dependence of the ellipsometric parameters of reflected light on the orientation of the optical axis relative to the plane of incidence [10717-63]

1071718 Wave propagation characteristics in the cavity with hyperbolic medium [10717-68]

1071719 To the theory of hybrid modes of the discrete spectrum in finite structures with nanocrystalline films [10717-202]

$107171 \mathrm{~A}$ Simulation and development of novel slow-wave structures for miniaturized THz-band vacuum-tube devices [10717-95]

$107171 \mathrm{~B}$ Dynamics of the optical field in the ring cavity with nonlinear metamaterial and timedelayed feedback [10717-176]

\section{PHOTONICS OF RANDOMLY INHOMOGENEOUS MEDIA}

10717 1C Bubble statistics in aged wet foams and the Fokker-Planck equation [10717-24]

10717 ID Evolution of the scattering anisotropy of aged foams in the wet-to-dry transition [10717-32] 
10717 IE Parametric presentation of dielectric function of laser pumped wide-zone semiconductor material: does this function satisfy the Kramers-Kronig relations? [10717-33]

10717 IF Diffusing light probing of aged wet foams [10717-82]

10717 1G Peculiarities of the statistics of spectrally selected fluorescence radiation in laser-pumped dye-doped random media [10717-122]

10717 1H Spatially resolved speckle-correlometry of sol-gel transition [10717-130]

1071711 Structure changes in metastable and unstable foams probed by multispeckle diffusing light spectroscopy [10717-185]

BRAIN DYNAMICS: ANALYSIS, MODELING, COMPUTATIONS

$107171 \mathrm{~J} \mathrm{Recognition} \mathrm{of} \mathrm{neural} \mathrm{brain} \mathrm{activity} \mathrm{patterns} \mathrm{correlated} \mathrm{with} \mathrm{complex} \mathrm{motor} \mathrm{activity}$ [10717-138]

$107171 \mathrm{~K}$ Analysis of psycho-physiological features of a subject in simple tests with the registration of electroencephalograms [10717-137]

$10717 \mathrm{lL}$ Analysis of the features of untrained human movements based on the multichannel EEG for controlling anthropomorphic robotic arm [10717-71]

$107171 \mathrm{M}$ Optimal spatiotemporal representation of multichannel EEG for recognition of brain states associated with distinct visual stimulus [10717-125]

10717 iN Detection of different states of sleep in the rodents by the means of artificial neural networks [10717-94]

1071710 Brain states recognition during visual perception by means of artificial neural network in the different EEG frequency ranges [10717-88]

10717 IP Multifractal analysis of real and imaginary movements: EEG study [10717-35]

$107171 Q$ Reconstruction of dynamical systems from resampled point processes produced by neuron models [10717-25]

10717 IR Brain-computer interface on the basis of EEG system Encephalan [10717-70]

10717 iS Raindrops of synaptic noise on dual excitability landscape: an approach to astrocyte network modelling [10717-129]

10717 IT Proepileptic patterns in EEG of WAG/Rij rats [10717-121]

$107171 \mathrm{U}$ Brain tissues volume measurements from 2D MRI using parametric approach [10717-113]

10717 IV The lymphatic mechanisms of brain cleaning: application of optical coherence tomography and fluorescence microscopy [10717-151] 
10717 IW On trans-parenchymal transport after blood brain barrier opening: pump-diffuse-pump hypothesis [10717-148]

10717 IX Wavelet-domain de-noising of OCT images of human brain malignant glioma [10717-83]

$107171 Y$ Optical coherent tomography and fluorescent microscopy for the study of meningeal lymphatic systems [10717-152]

\section{COMPUTER-ASSISTED MICROCIRCULATION STUDIES}

1071712 Highly localized laser-induced vascular responses [10717-103]

1071720 The estimation of hemodynamic signals measured by fNIRS response to cold pressor test [10717-80]

1071721 Dynamical mechanisms of conducted vasoreactivity: minimalistic modeling study [10717-147]

1071722 Towards optical control of single blood platelet activation [10717-8]

1071723 Low-frequency dynamics of autonomic regulation of circulatory system in healthy subjects [10717-146]

1071724 Non-contact method of search and analysis of pulsating vessels [10717-116]

1071725 Analysis of cerebral vessels dynamics using experimental data with missed segments [10717-26]

1071726 Numerical modeling of dynamics of heart rate and arterial pressure during passive orthostatic test [10717-141]

1071727 Automated analysis of plethysmograms for functional studies of hemodynamics [10717-192]

\section{ADVANCED METHODS IN BIOCOMPUTING}

1071728 MATLAB for laser speckle contrast analysis (LASCA): a practice-based approach [10717-144]

1071729 Nonlinear dynamics of the complex multi-scale network [10717-111]

10717 2A Mechanisms for the target patterns formation in a stochastic bistable excitable medium [10717-127]

10717 2B Self-organization in multilayer network with adaptation mechanisms based on competition [10717-117]

10717 2C Creation of anatomical models from CT data [10717-18] 
10717 2D Power-law statistics of neurophysiological processes analyzed using short signals [10717-34]

$107172 \mathrm{E} \quad$ Numerical simulation of coherent resonance in a model network of Rulkov neurons [10717-108]

10717 2F Visualization of 3D CT-based anatomical models [10717-17]

$107172 \mathrm{G}$ Indirect synchronization control in a starlike network of phase oscillators [10717-178]

$107172 \mathrm{H} \quad$ Synchronization of oscillations in coupled multimode optoelectronic oscillators: bifurcation analysis [10717-133]

107172 Reconstructions of parameters of radiophysical chaotic generator with delayed feedback from short time series [10717-143]

10717 2J Mathematical model of bone drilling for virtual surgery system [10717-15] 


\section{Authors}

Numbers in the index correspond to the last two digits of the seven-digit citation identifier (CID) article numbering system used in Proceedings of SPIE. The first five digits reflect the volume number. Base 36 numbering is employed for the last two digits and indicates the order of articles within the volume. Numbers start with 00, 01, 02, 03, 04, 05, 06, 07, 08, 09, 0A, OB...0Z, followed by 10-1Z, 20-2Z, etc.

Abdurashitov, A. S., 1V, 1Y, 25

Adamov, A. A., 03, 09

Adilova, Asel B., OA

Agranovich, I., IV, IY

Alaytsev, Innokentiy K., 2C, 2F, 2J

Aleksandrova, P. V., 1X

Alonova, M. V., 1G

Andreev, Andrey V., 10, 29, 2E

Ansari, M. A., 20

Astakhov, E. I., 08

Avtomonov, Yuri N., 24

Azyazov, Valeriy Nikolaevich, 05, 01

Badarin, Artem, IR

Balakin, M., 2H

Baranov, M. S., 09

Barantsev, Konstantin, OC

Bashkirov, Eugene K., OT, OU, OX

Benedik, Andrey I., IA

Beshplav, S.-I. T., IX

Bezruchko, B. P., 21

Biryukov, A. A., OS

Blaschke, David B., 02

Bodrova, A., IV, IY

Borovkova, E. I., 23

Brazhe, Alexey R., 15

Burlov, Sergey A., OV

Burmak, Ludmila, $\mathrm{OH}$

Butt, M. A., 04

Chernomyrdin, N. V., IX

Chernyshov, Aleksandr Konstantinovich, 01

Chuluunbaatar, O., 10, 12

Danilova, Tatyana V., 2C, 2F, 2J

Davidovich, Mikhael V., 14, 15

Degtyarev, S. A., OL

Degtyareva, Ya. V., OS

Demidova, Anastasia $V_{\text {., }}$ OY

Derbov, V. L., 10, 12

Divakov, D. V., 11

Dmitriev, Vadim V., 02

Dobdin, S. Y., 08

Dolganova, I. N., IX

Dubyanskaya, E. N., IX

Dvoryatkina, M., IY

Dykin, Viacheslav, $1 \mathrm{~N}$

Efremova, Tatiana YU., 1 J, 1K, 1L, 1M

Fazliazar, E., 20

Fedosov, Ivan V., 1V, 1Y, 1 Z

Fomchenkov, S. A., OQ

Galushko, T. A., 23

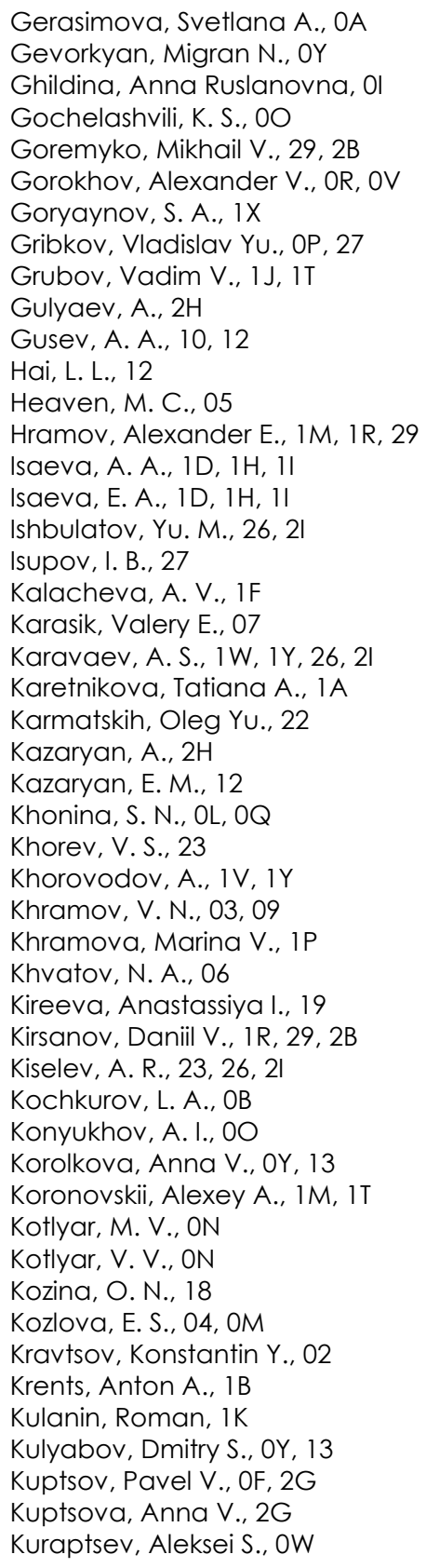


Kurkin, Semen A., $1 \mathrm{~J}$

Kurlov, V. N., $1 \mathrm{X}$

Kurochkin, Maxim A., 1 Z

Kurths, J., IV

Kuryshova, Ekaterina A., 21

Lasarev, Vladimir A., 07

Levenets, Sergey A., 02

Litovka, Yu. V., $1 \mathrm{U}$

Litvinov, Andrey, OC

Lovetskiy, K. P., 10

Lunev, Nikolai Nikolaevich, 01

L'vov, A. A., $1 \mathrm{U}$

Macheev, M. S., 11

Machikhin, Alexander, $\mathrm{OH}$

Makarov, Vladimir V., 29, 2B

Maksimenko, Vladimir A., 1L, 1P, 1R

Malykh, M. D., 0Z, 11

Manturov, Alexey O., 2C, 2F, 2J

Mareev, Gleb O., 2C, 2F, 2J

Mareev, Oleg V., 2C, 2F, 2J

Markova, N. S., IF

Mavrin, P. A., 00

Mebel, A. M., 05

Medvedkov, I. A., 06

Melnikov, Leonid A., OK, 00, 18

Melnikova, Maria M., OA

Mikheyev, Pavel Anatolyevich, 06, 0l

Moiseev, Anton Vladimirovich, 16, 17

Moiseeva, Natalia Michailovna, 16, 17

Molevich, Nonna E., 1B

Moskalensky, Alexander E., 22

Musatov, Vyacheslav Yu., 1J, 1M, 1N, 10

Nalimov, A. G., ON

Namykin, A., IV, IY

Nedaivozov, Vladimir O., 1R, 1T, 2B

Nefedov, I. S., 18

O'Faolain, L., ON

Panfyorov, Anatoly D., 02

Pantyukov, A. V., $1 \mathrm{H}$

Parshkov, Oleg M., OJ

Pavlov, Alexey N., 1P, 1Q, 1V, 1Y, 25, 2D

Pavlova, Maria V., $1 G$

Pavlova, Olga N., 1Q, 25, 2D

Pchelintseva, Svetlana V., $1 \mathrm{~L}$

Pershin, A. A., 05

Pisarchik, Alexander N., 1L, 1M, 1N, 1P, 2E

Pitsik, Elena N., 1N, 2B

Popov, Evgeniy, OC

Popov, Yu. V., 10

Porfirev, A. P., OL, OQ

Postnikov, Eugene B., 1W, 28

Postnov, Dmitry E., 1S, 1W, 1Z, 21, 24, 28, 2A, 2I

Potapov, A. A., $1 \mathrm{X}$

Pozhar, Vitold, $\mathrm{OH}$

Protasov, Pavel, $1 \mathrm{~K}$

Razukov, Vadim A., OK

Reshetov, I. V., $1 \mathrm{X}$

Rogatina, Kristina $\vee ., 21$

Rozhnev, Andrey G., OA, 1 A

Rudenok, Igor P., 19
Runnova, Anastasiya E., 1J, 1K, 1L, 1M, 10, 1P, 2D, 2E

Ryskin, Nikita M., OA, $1 \mathrm{~A}$

Sagatova, V., IV, IY

Samorodina, T. V., 1C, 1D, 1 E

Saranceva, E., $1 Y$

Sarkisyan, H. A., 12

Schurkin, E. V., 00

Semyachkina-Glushkovskaya, O. V., 1V, 1W, 1Y, 25,21

Sevastianov, A. L., 11

Sevastianov, Leonid A., OY, OZ, 11

Shareef, Ali Esmat, $1 Y$

Shihalov, G. M., 25

Shirokov, A., IV, 1 Y

Shleenkov, M. A., OS

Shushunova, N., IV, IY

Sindeeva, O., IV, IY

Sitnikova, Evgenia Yu., $1 T$

Skazkina, V. V., 23

Skripal, A. V., 08

Slavnetskov, I. O., $1 \mathrm{~F}$

Smirnov, Vitaly A., OD, OE

Smolyansky, Stanislav A., 02

Sokolov, Igor M., OW

Spiryova, Darya V., 22

Stafeev, S. S., ON

Stiukhina, Elena S., 1 Z

Sysoliatin, A. A., 00

Tarabrin, Mikhail K., 07

Terentyuk, Artem G., 1 A

Tiutiunnik, A. A., $0 Z$

Tolstov, G. I., 06

Tomilov, Sergey M., 07

Torbin, A. P., 05

Torgashov, Gennadiy V., IA

Torgashov, Roman A., $1 \mathrm{~A}$

Toropova, O. A., $1 \mathrm{U}$

Tsoy, Maria O., 24, 28

Tuchin, Valery $V_{\text {., }} 07,1 \mathrm{X}, 1 \mathrm{Y}$

Turkin, Yaroslav $\vee .$, OF

Tyshkun, Alexandra $\mathrm{V} ., \mathrm{OA}$

Tzyipin, D. V., 1C, 11

Ulanova, M. V., 1V, 1Y, 25

Usanov, D. A., 08

Ushakova, E. V., $1 G$

Ushakova, O. V., 11

Velieva, Tatyana R., 13

Verisokin, Andrey Yu., 1S, 2A

Verveyko, Darya V., 1S, 2A

Vinitsky, S. I., 10, 12

Volchkov, S. S., OG, $1 \mathrm{E}$

Vorob'ev, Alexei Yu., 22

Vorobiev, Anatoly M., OX

Vostrikova, Liubov I., OD, OE

Yarovoy, $\mathrm{O} ., 2 \mathrm{H}$

Yarunova, Elizaveta A., 1B

Yukhnovsky, Lukash, 02

Yuvchenko, S. A., OG, 1C, 1D, 1E, 1F, 1G, 11

Zagidullin, M. V., 06 
Zatrudina, Rimma Sh., OP, 27

Zaytsev, K. I., $1 \mathrm{X}$

Zhuravlev, Maxim O., 1J, 1K, 1L, 10

Zimnyakov, Dmitry A., 0G, 1C, 1D, 1E, 1F, 1G,

$1 \mathrm{H}, 1 \mathrm{I}$

Proc. of SPIE Vol. 10717 1071701-11

Downloaded From: https://www.spiedigitallibrary.org/conference-proceedings-of-spie on 26 Apr 2023 Terms of Use: https://www.spiedigitallibrary.org/terms-of-use 
Proc. of SPIE Vol. 10717 1071701-12 Downloaded From: https://www.spiedigitallibrary.org/conference-proceedings-of-spie on 26 Apr 2023
Terms of Use: https://www.spiedigitallibrary.org/terms-of-use 


\title{
Conference Committee
}

\author{
Symposium Chair
}

Valery V. Tuchin, Saratov National Research State University (Russian Federation) and National Research Tomsk State University, (Russian Federation) and Institute of Precision Mechanics and Control, RAS (Russian Federation)

Symposium Secretary

Elina A. Genina, Saratov National Research State University (Russian Federation) and National Research Tomsk State University (Russian Federation)

Conference Chairs

Vladimir L. Derbov, Saratov National Research State University (Russian Federation)

Dmitry E. Postnov, Saratov National Research State University (Russian Federation)

Conference Secretaries

Andrey I. Konyukhov, Saratov National Research State University (Russian Federation)

Elena S. Stiukhina, Saratov National Research State University (Russian Federation)

Conference Program Committee

Boris P. Bezruchko, Saratov National Research State University (Russian Federation)

Alexander V. Gorokhov, Samara University (Russian Federation)

Bogos B. Joulakian, Université de Metz (France)

Alexander P. Kuznetsov, Saratov Division of the Institute of Radio-Engineering and Electronics, RAS (Russian Federation)

Marian Marciniak, National Institute of Telecommunications (Poland)

Leonid A. Melnikov, Saratov State Technical University (Russian Federation)

Alexander B. Neiman, The Ohio University (United States)

Alexander P. Nizovtsev, B.I. Stepanov Institute of Physics of National Academy of Sciences of Belarus (Belarus)

Yuri V. Popov, M.V. Lomonosov Moscow State University (Russian Federation)

Vladimir P. Ryabukho, Saratov National Research State University (Russian Federation), Institute of Precision Mechanics and Control, RAS (Russian Federation) 
Oxana V. Semyachkina-Glushkovskya, Saratov National Research State University (Russian Federation)

Anatoly V. Skripal, Saratov National Research State University

(Russian Federation)

Olga V. Sosnovtseva, University of Copenhagen (Denmark)

Sergue I. Vinitsky, Joint Institute for Nuclear Research (Russian Federation)

Aleksey M. Zheltikov, M. V.Lomonosov Moscow State University

(Russian Federation)

\section{Session Chairs}

$1 \quad$ Laser Physics and Photonics XVIII

Vladimir L. Derbov, Saratov National Research State University

(Russian Federation)

2 Computational Biophysics and Analysis of Biomedical Data IV

Dmitry E. Postnov, Saratov National Research State University

(Russian Federation) 


\section{Introduction}

The 5th International Symposium on Optics and Biophotonics (Saratov Fall Meeting: SFM 17) was held in Saratov, Russian Federation, 26-30 September 2017 with over 500 participants from the Russian Federation, United States, Canada, and Europe, Asia, and Pacific Ocean countries. It covered a wide range of modern problems of fundamental and applied optics, laser physics, photonics, and biomedical optics.

This volume includes selected papers from the following conferences and workshops organized in the framework of the symposium:

Laser Physics and Photonics XVIII

Vladimir L. Derbov (Chair)

Computational Biophysics and Analysis of Biomedical Data IV

Dmitry E. Postnov (Chair)

The first part of the volume, devoted to laser physics and photonics, begins with the papers related to lasers and their applications, including high-power chemical lasers, THz sources, and a variety of semiconductor laser systems. Among the applications: the fundamental problem of particle creation from a vacuum in the super-intense laser field is worth particular interest. The next two sections include the papers on nonlinear optical interactions, beam and pulse propagation, and image formation. The newest and most interesting results here are related to soliton dynamics, propagation of polarized pulses under the conditions of self-induced transparency, as well as the formation and application of nontrivial laser beams possessing optical vortices.

The Saratov Fall Meeting traditionally gives the floor to the discussion of the urgent problems of quantum optics. In the present volume, the papers related to quantum optics and non-classical light mainly focused on theoretical interpretation of fundamental quantum optical experiments, particularly those related to the formation and application of entangled quantum states, which are expected to play a crucial role in the implementation of quantum computers, encryption, and networks. A variety of new objects exposed to laser irradiation and novel light-matter interactions beyond the limits of classical optics that belong to a more general field of photonics, naturally, require novel theoretical and numerical approaches. Alongside traditional software development, and computer simulations of particular systems interacting with laser radiation, the papers of the present volume consider a fundamental issue of geometrization of Maxwell theory and its practical outcome.

As compared to the analogous volume of SFM 2016 Proceedings (Proceedings volume 9917), two new sections have been added. One section is devoted to 
electrodynamics of photonic systems; particularly the interaction of electromagnetic waves with artificial media including metamaterials. The laser section was comprised of papers reporting the analysis of randomly inhomogeneous media (foams, gel suspensions, etc.) using polarization optics, light diffusion, and speckle correlometry techniques.

The second part of the volume was devoted to computational biophysics and analysis of biomedical data. Here, the hot topic appeared to be the variety of measurement techniques and data processing algorithms relevant to brain studies. Specifically, the sophisticated methods of EEG analysis are presented in order to link the recorded signals with patterns of complex motor activity, or to test the basic psycho-physiological features of a person, or to provide the effective control of anthropomorphic robotic arm. Another notable trend in this field was based on increasing evidence that the account of integrity of brain functions can open the door to future research progress. The electrical activity of a brain alters its physiological state in terms of ionic concentrations, and vice versa, the effectiveness of drainage of brain tissues supports or complicates normal information processing. In this regard, the number of presented studies were devoted to the study of meningeal lymphatic system, to the brain tissues volume measurements, and to modeling of astrocyte network functions.

Another important problem addressed in the volume was computational issues relevant to microcirculation studies. The presented problem-specific algorithms and numerical methods range from non-contact method of search and analysis of pulsating vessels, automated analysis of plethysmograms or fNIRS response, through modeling studies on conducted vasoreactivity and heart-rate dynamics during orthostatic test.

Last but not least there were contributions of general interest providing the receipts or just the hints for the variety of biocomputing needs. Worth mentioning is the paper on practice-based approach to LASCA, as well as a description of generic mechanisms for the target patterns formation in a stochastic bistable excitable media.

This is the second volume of the Saratov Fall Meeting 2017 Proceedings. The preface to the first volume, Optical Technologies in Biophysics \& Medicine XIX (volume 10716), edited by Elina A. Genina and Valery V. Tuchin, provided the reader with thorough and impressive information about the entire event of Saratov Fall Meeting 2017.

The editors of this volume thank all of the authors for their contributions to the symposium, especially the plenary, invited and Internet lecturers for their exciting presentations. We are also grateful to all the sponsoring organizations and programs that efficiently supported this meeting, especially to: Russian Foundation for Basic Research; Russian Academy of Sciences; SPIE; OSA-The Optical Society; IEEE; Russian Technology Platforms "The Medicine of the Future" 
and "Photonics"; European Technology Platform "Photonics21"; EPIC - European Photonics Industry Consortium; LLC SPE "Nanostructured Glass Technology" (Russian Federation); and RME "INJECT" LLC (Russian Federation).

Vladimir L. Derbov Dmitry E. Postnov 
Proc. of SPIE Vol. 10717 1071701-18

Downloaded From: https://www.spiedigitallibrary.org/conference-proceedings-of-spie on 26 Apr 2023 Terms of Use: https://www.spiedigitallibrary.org/terms-of-use 


\section{Organizers}

Saratov State National Research University of Russia (Russian Federation)

Research-Educational Institute of Optics and Biophotonics at Saratov State University (Russian Federation)

International Research-Educational Center of Optical Technologies for Industry and Medicine "Photonics" at Saratov State University (Russian Federation)

Institute of Biochemistry and Physiology of Plants and Microorganisms, RAS

(Russian Federation)

Institute of Precision Mechanics and Control, RAS (Russian Federation)

Saratov State Medical University n.a. V.I. Razumovsky (Russian Federation)

Tomsk State University National Research University of Russia (Russian Federation)

Volga Region Center of New Information Technologies (Russian Federation)

SPIE Student Chapter of Saratov State University (Russian Federation)

SPIE Student Chapter of Bauman State Technical University (Russian Federation)

OSA Student Chapter of Saratov State University (Russian Federation)

Saratov/Penza IEEE Chapter (Russian Federation) 
Proc. of SPIE Vol. 10717 1071701-20 Downloaded From: https://www.spiedigitallibrary.org/conference-proceedings-of-spie on 26 Apr 2023
Terms of Use: https://www.spiedigitallibrary.org/terms-of-use 